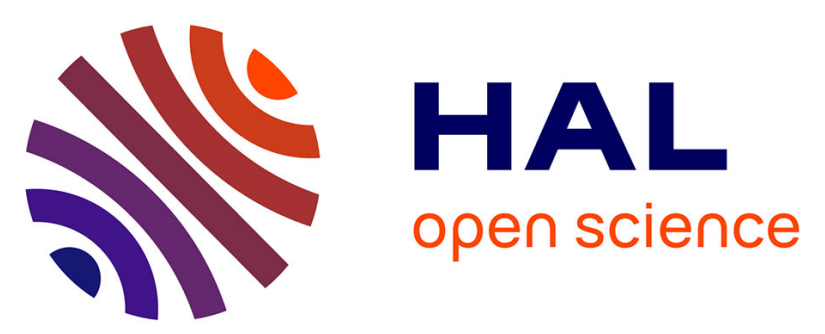

\title{
Ethological evaluation of Human-Robot Interaction: are children more efficient and motivated with computer, virtual agent or robots?
}

Céline Jost, Vanessa André, Brigitte Le Pévédic, Alban Lemasson, Martine Hausberger, Dominique Duhaut

\section{To cite this version:}

Céline Jost, Vanessa André, Brigitte Le Pévédic, Alban Lemasson, Martine Hausberger, et al.. Ethological evaluation of Human-Robot Interaction: are children more efficient and motivated with computer, virtual agent or robots?. IEEE ROBIO 2012 - IEEE International Conference on Robotics and Biomimetics2012, Dec 2012, Guangzhou, China. pp.1368-1373. hal-00745660

\author{
HAL Id: hal-00745660 \\ https://hal.science/hal-00745660
}

Submitted on 26 Jan 2013

HAL is a multi-disciplinary open access archive for the deposit and dissemination of scientific research documents, whether they are published or not. The documents may come from teaching and research institutions in France or abroad, or from public or private research centers.
L'archive ouverte pluridisciplinaire HAL, est destinée au dépôt et à la diffusion de documents scientifiques de niveau recherche, publiés ou non, émanant des établissements d'enseignement et de recherche français ou étrangers, des laboratoires publics ou privés. 


\title{
Ethological Evaluation of Human-Agent Interaction: are children more efficient and motivated with computer, virtual agent or robots?
}

\author{
C. Jost, V. André, B. Le Pévédic, A. Lemasson, M. Hausberger and D. Duhaut
}

\begin{abstract}
Nowadays, robots and virtual agents become companions for humans. They seem to have distinct roles in the Human-Agent Interaction. Thus, when developing a new application, it is judicious to wonder which the better is. In the Robadom project, a homecare robot has to assist elderly at home. The robot provides cognitive stimulation game. We developed StimCards, a cognitive card-based game. The principle question is: is the robot the best interlocutor in this context? This paper presents an evaluation of StimCards. Participants are children because French elderly is reluctant to robots and because they will be the future hypothetical users.
\end{abstract}

\section{INTRODUCTION}

$\mathrm{W}$ ORKING on robotic companions is a new challenge of this century. Some movies show the future "super robots" which will independently live with humans. But in reality, the technology is far from this result. Nowadays, searchers try to create homecare robots which can accompany people in their daily life. For example, the Robadom project [1] aims at designing a robot which assists elderly at home. Its role is to manage the shopping list, appointments, meetings, and medication taking. The robot could be an intermediate between the person and his/her family. Its specialty is to provide encouragements and coaching during cognitive stimulation exercises.

This paper focuses on one of these missions: cognitive stimulation exercises. We develop an application which provides this kind of exercises: StimCards. This game is composed of cards, a webcam, a computer and a Graphical User Interface (GUI) and a computing interlocutor which orchestrates the game: the computer, a virtual agent, a robot.... The card contains a barcode which encodes a question, a set of suggested answers and the true answer. The webcam read the barcode and transmits data to the GUI which displays cards data for users. The game is completely configurable. It is possible to personalize questions and answers. Thus, this product is interesting because it can easily be adapted to numerous different people. This paper focuses on StimCards evaluation.

Our work has two main concerns: StimCards acceptability and the choice of the best interlocutor for human. A focus

Manuscript received July 30, 2012. This work has been supported by French National Research Agency (ANR) through TecSan program (project Robadom nANR-09-TECS-012).

C. Jost, B. Le Pévédic and D. Duhaut are with the University of South Brittany in the Lab-STICC laboratory. Vannes, France.

V. André, A. Lemasson and M. Hausberger are with the University of Rennes 1 in the "Ethologie Animale et Humaine" laboratory, Rennes, France. group, composed of French old people, showed a low level of acceptance concerning humanoid robots [2]. First, they only imagined interaction with small robots which look like a "teapot". Second, they perceived the robot as a human substitute which makes them afraid. Their reluctance seemed to be a bias for this experimentation. In order to obtain a second point of view, we decided to experiment StimCards on 10 years children for two reasons. First, they are not reluctant to new technologies because they always knew it. Second, the current children are the future elderly and represent some possible future StimCards users.

On the one hand, StimCards acceptability has been evaluated [3]. A questionnaire tested children interest, StimCards usability and capability of personalization. Results were positive. Children really liked this game and wanted to keep playing with it. They found it easy to use. And they urged to personalize the game. The results indicated that StimCards is an appropriate tool for humancomputer interaction in an educational game context.

On the other hand, the study introduced some interlocutors to children: the computer which displays cards data, a virtual agent, a metallic robot and a plush robot. Indeed, another challenge of this century deals with virtual character. It makes possible an interaction with human without a costly robot. Robots and Virtual characters have a distinct role and no one is better than others [4]. (See a state of the art in [5]). Thus, it is important to check which interlocutors is the best for cognitive training exercises. A questionnaire asked children about their preference. The preliminary results [3] showed that robots are preferred by children. But it was not possible to determine either the metallic robot or the plush robot was the favorite one.

To complete this preliminary study, the experimentation has been filmed. The films were given to ethologists to be analyzed in order to determine the favorite interlocutor. The ethology discipline is the study of animal behaviors (including human beings). Thus ethologists can interpret movements, postures, facial expression and so on. Their study, which used questionnaire, observation and performance computation, determined that the metallic robot was the favorite one to improve children performance.

This article presents the related work about comparison between virtual agent and robots. Then the section III presents the computing setting used in this experimentation. The section IV describes the experimentation while the section V details the results. Section VI gives discussion and conclusion. 


\section{RELATED WORK}

Concerning social robots, Kidd [6] showed the importance of physically presence. It makes the robot more trustable and altruistic. However there is no effect on engagement. With a lot of interaction, the robot is more credible and persuasive. It could be interesting to know in which context the robot is better than virtual character and vice versa. The literature shows six recent studies which compare real robot and virtual one. Table I gives a concise overview of each study. Three studies established that there is no difference between real and virtual. A study determined that virtual is better and two studies determined that real is better.

Concerning equality between real and virtual, the first study [7][8] made the comparison between a robot and a screen agent recommendation on decision's making in the context of color-name selection task. This experimentation determined that there is no difference between real and virtual agent. But they showed that its effect depends on interaction environment. A 3D body has effect in a 3D environment; a 2D body has effect in a 2D environment; but a $2 \mathrm{D}$ body has no effect in a $3 \mathrm{D}$ environment and vice versa. The second experimentation [9] studied the effect of physical embodiment. Their results indicated that physical embodiment is evaluated more positively than disembodied one if people can touch objects. If people cannot touch the physical embodiment, this one is evaluated less positively than disembodied one. Tactile interaction is important. Moreover they highlighted that social agents are more attractive to lonely people. The third experimentation [10] studied the impression of real robot and virtual robot based on the personal space of people. They did not find any difference between real and virtual but established that people need more space with robot than with virtual agent.

Concerning the case where virtual characters are better, the study [11] made the comparison between a real robot and a virtual one in a learning companion system. This study revealed that people were more concentrated with the virtual robot.

Concerning the case where real robots were better, the first study [12] made the comparison between real and virtual robot and between young (mean 20.6 years old) and old (mean 68.7 years old) people. Results showed that the elderly take into account the robot more than the youth. The elderly impressions are more positive about the real robot. The young people have less attachment to the robot virtual. In general, the elderly have more attachment for virtual robot than the youth. The second experimentation [13] made the comparison between real robot and computer in the context of musical cognitive game. This study revealed that social interaction and task performance are improved thanks to interaction with the robot.
TABLE I

STUDIES ON COMPARISON BETWEEN REAL AND VIRTUAL EFFECTS

\begin{tabular}{lcllcc}
\hline \hline Study & Year & Location & Participants & Method & $\begin{array}{c}\text { Best } \\
\text { interlocutor }\end{array}$ \\
\hline$[7][8]$ & 2004 & Japan & Everyone & $\mathrm{O}+\mathrm{Q}$ & $\mathrm{R}=\mathrm{V}$ \\
{$[9]$} & 2006 & USA & Undergraduate & $\mathrm{Q}$ & $\mathrm{R}=\mathrm{V}$ \\
{$[10]$} & 2009 & Japan & Young & $\mathrm{Q}$ & $\mathrm{R}=\mathrm{V}$ \\
{$[11]$} & 2007 & Taiwan & $\begin{array}{l}\text { Elementary } \\
\text { Elderly \& }\end{array}$ & $\mathrm{Q}$ & $\mathrm{V}$ \\
{$[12]$} & 2009 & Japan & $\begin{array}{l}\text { Young } \\
\text { Elderly with }\end{array}$ & $\mathrm{O}+\mathrm{Q}$ & $\mathrm{R}$ \\
\hline 13$]$ & 2009 & USA & dementia & $\mathrm{R}$ \\
\hline \hline
\end{tabular}

$\mathrm{O}=$ observation, $\mathrm{Q}$ = questionnaire, $\mathrm{R}=$ Real and $\mathrm{V}=$ Virtual.

These results show that robot and virtual agents are both important and should be specialized to be more efficient. But it is not possible to conclude about human acceptance because of the Asiatic and American cultures.

\section{STIMCARDS}

\section{A. Presentation}

StimCards is an interactive game which is composed of: cards with barcode, a webcam, a Graphical User Interface and, optionally, a virtual or real companion (see Fig. 1). To play, gamers must show a card to the camera which recognizes the card and displays its environment in the GUI. Gamers give their answers among suggested answers. Other digital devices can be added to the game, such as virtual character or robots.

StimCards can be adapted with others questions. People only have to change the card file description which is a XML file. This configuration file contains: the question label and a associated picture (optional), a question type (multiple choice question, open question, yes/no question...), a card category (entertainment, sciences, math...), colors (GUI background, font), a set of clues which can help gamers, a set of suggested answers (text and/or picture) and the true answer. These data, except the true answer, are displayed in StimCards GUI. Fig. 2 shows an example of a loaded card.

\section{B. Tested environments}

The experimentation objective was to determine the favorite interlocutor for children. Thus we decided to compare four different environments, represented in Fig. 3. In each environment, we added a tactile tablet to StimCards

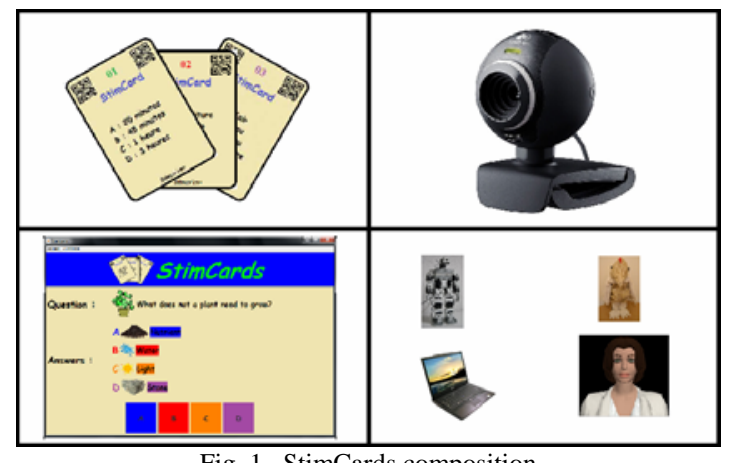

Fig. 1. StimCards composition 
in order to give answer.

A computer only displayed StimCards GUI and the

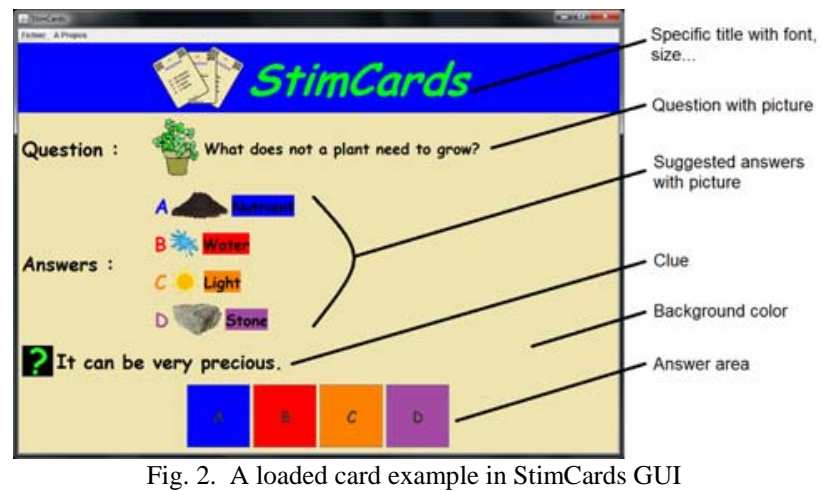

camera view. Users did not be able to touch this computer. They were only able to communicate with the tactile tablet which displayed a specific answer frame. The first environment (A) was the control condition managed by the computer. The interaction was between the gamer and the computer. The second environment (B) was managed by an embodied conversational agent called GRETA [14]: the character. The third environment $(\mathrm{C})$ introduced a small humanoid robot called Bioloïd: the robot. And the last environment (D) showed the same robot dressed up as a plush chicken: the animal. In each environment, the text synthesis used the same French voice in order to avoid bias: ScanSoft Virginie_Dri40_16kHz. We used Windows sapi api to make computer, agent and robots speak.

\section{Experimentation exercises}

Exercises were created with children teachers in order to have appropriate difficulty level. We chose mental computation exercises because they do not require specific cultivation and because each child had these skills.

A session exercise had five difficulty levels. To create levels, we decided to use only one operator: addition because it was too difficult to create exercises with several operators. Which one was the most easy to use? Table II shows the construction of the five levels. Progress is constant.

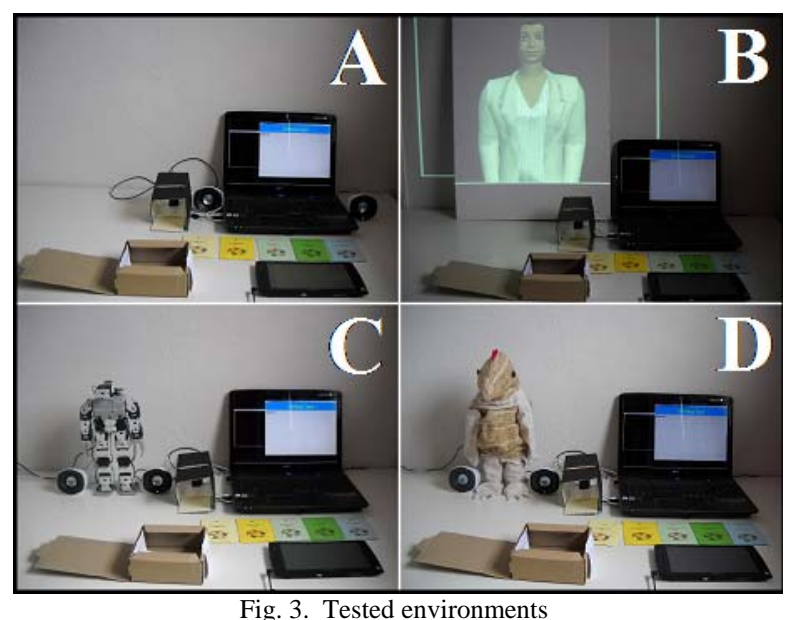

TABLE II

CONSTRUCTION OF GAME LEVELS

\begin{tabular}{cll}
\hline \hline Level & \multicolumn{1}{c}{ Construction } & \multicolumn{1}{c}{ Example } \\
& & \\
\hline 1 & $\mathrm{X}+\mathrm{X}$, result $<10$ & $5+3 ; 2+7$ \\
2 & $\mathrm{X}+\mathrm{X}$, result $>10$ & $8+7 ; 5+9$ \\
3 & $\mathrm{X}+\mathrm{XX}$, result $<50$ & $32+9 ; 27+6$ \\
4 & $\mathrm{XX}+\mathrm{XX}$, result $<50$ & $43+28 ; 37+16$ \\
5 & $\mathrm{XX}+\mathrm{XX}$, result $>50$ & $75+69 ; 64+57$ \\
\hline \hline
\end{tabular}

\section{EXPERIMENTATION}

\section{A. Objective}

The experimentation objective was to use ethological methodology to evaluate human-robot interaction in order to determine which interlocutor is the most efficient in a cognitive task. In this study, several approaches were crossed to increase results reliability: questionnaire, observation and performance computation. The questionnaire asks questions concerning StimCards acceptability and concerning each environment [3]. Observation consisted to note each posture (curved, relaxed, straight, and tense) and each look. Performance computation consisted to note the response time and the numbers of mistakes made during the exercise.

\section{B. Participants}

Participants were pupils in the equivalent of the 4th English grade (mean age: 10.27 years old). They came from two different schools from two different French cities. In this study, results of 51 children (26 girls and 25 boys) were analyzed. In the previous study, 52 children were taken into account. It was not a problem for questionnaire analysis. But, this study includes observation analysis and we had to remove a child. It was not possible to analyze her behavior because of materials problems during a session.

\section{Global Setting}

The setting which has been described in [3] is written here too to make a good understanding of the work. To have a similar experimental setting in all conditions and with all participants, the experimentation was conducted in a 1.60 meters cubic room, closed by green curtains. Green has been chosen to increase luminosity in the room and because it is bright and calming. Fig. 4. shows the organization in this room.

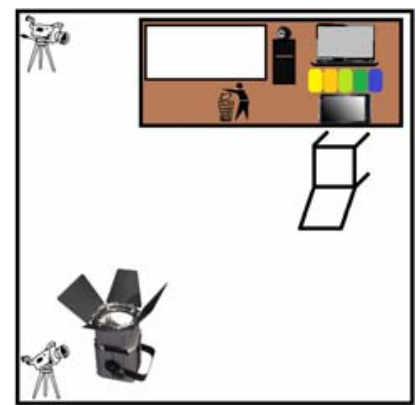

Fig. 4. Experimental setting - room 


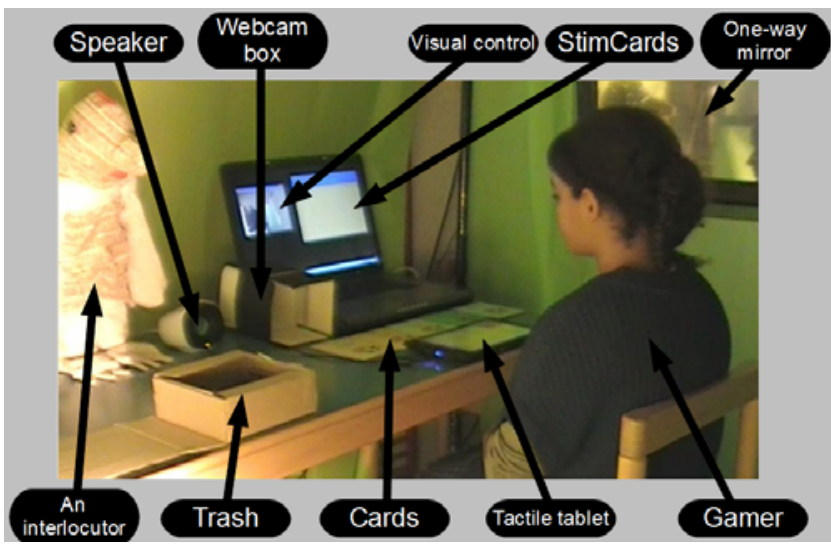

Fig. 5. Experimental setting - desk

Children were isolated in the room. The both lateral curtains have one way mirrors to make sure the experimentation went smoothly. Fig. 5. illustrates the experimental setting. A desk and a chair were at the end of the room, back to the entrance. Two cameras filmed the interaction. The first one filmed children face. The second one filmed from head to knees in order to see legs and hands movements and general posture. A projector illuminated the room. A computer displayed the StimCards GUI. Game cards were placed in front of the computer. There were five packages corresponding to the five difficulty levels: lightyellow, dark yellow, light-green, dark green and blue. A tactile tablet was placed in front of children. A camera was fixed in a black box, on the left of the computer. Children had to put a card in the box slit. The card was placed in front of the camera which read the barcode and treated the question. When children finished playing with a card, they throw it away in the trash box. The interlocutor was always placed at the computer left.

\section{Procedure}

The experimentation was composed of four 10 minutes sessions related to the four different interlocutors. Each participant played with each interlocutor.

The creation of the game scenario is described in [3]. We used a framework which is able to connect together all kinds of digital devices and allows programming easily the environment.

A session started with the interlocutor speech which allows explaining the rules and starting the game. During the introduction part, the interlocutor ensured several times that the participant understood explanations. The participant had to answer "yes" or "no". This part was controlled by a computing engineer who answered with an administration GUI by clicking "yes" or "no" buttons. It allows us simulating the vocal recognition without changing the scenario.

The gamer was asked to begin the game with a first level card. He/She had to show the card to the webcam. Thus, the barcode was recognized and data were able to be displayed by the GUI. At the same time, the interlocutor asked the question to the participant who had to answer with the tactile tablet. Fig. 6. shows the answer frame. Gamer had to type the addition result and then push the "VALIDER" button.

If the result was good, the interlocutor congratulated the participant and invited him/her to take a higher level card. If the result was false, the interlocutor encouraged the participant and invited him/her to take a similar level card.

The game was finished after 9 questions, which corresponds to the end of the fifth level cards if the participant gave only good results.

After each session, participants had to answer a questionnaire composed of 13 questions, which asked their impression on the interlocutor. At the end of the four sessions, participants had to answer general questions about the game and to speak about their favorite interlocutor.

To avoid a bias related to the order of interlocutors, sessions of both schools did not have the same order.

\section{RESUltS}

These results present four main analysis based on questionnaires, observation and computation performances. Each participant filled 4 questionnaires and a set of outcome questions. It represented 204 questionnaires with 13 questions and 51 questionnaires with 8 outcome questions. Concerning recording, each participant attended four sessions which corresponds to 40 minutes, filmed by two movie cameras. The total represented 68 hours.

This article presents main important results and does not detail the methodology. The whole results will be published in an ethologic journal.

Four interlocutors are compared to determine which one is the best to encourage children to do exercises. Interlocutors are called: computer, character, animal and robot (introduced in III.B).

\section{A. Questionnaire analysis}

A first analysis was based on the answers given by the questionnaires. Children classified the four interlocutors according their preference. The significant order of preference is: robot, animal, character and computer (G tests, $\mathrm{ddl}=1, \mathrm{P}<0,012$ ).

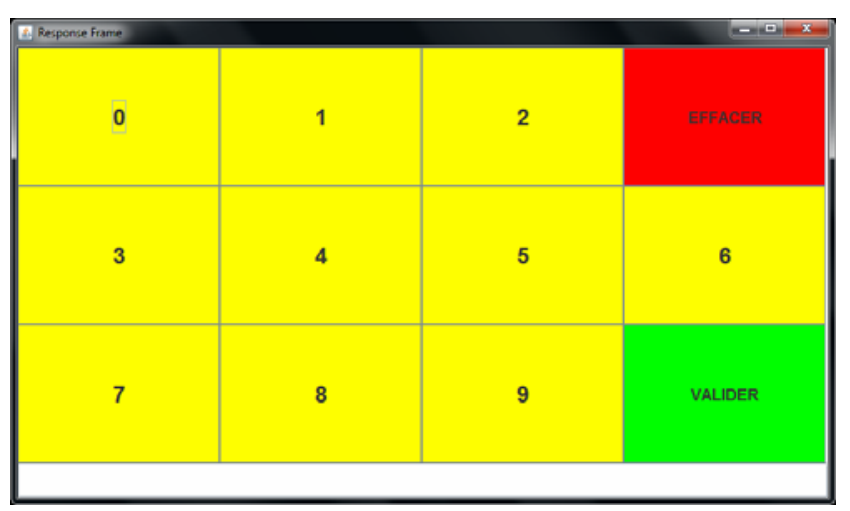

Fig. 6. Answer frame 


\section{B. Observation analysis: watching the computer}

This second analysis was based on the children behavior observed throughout the experimentation.

The first part of this study consisted to analyze children's look. The objective was to determine whether children had the same behavior in the presence of the computer, the character, the animal or the robot. Thus, we compared the time when children watched the computer in the four environments. Results indicated that this time decreased significantly in the presence of the character, the animal or the robot (Wilcozon's test, robot: $\mathrm{Z}=5.849, \mathrm{P}<0.0001$; animal: $\mathrm{Z}=4.602, \quad \mathrm{P}<0.0001$ and character: $\mathrm{Z}=5.005$, $\mathrm{P}<0.0001$, Fig. 7). Fig. 7 shows the percentage of the average time when children watched the computer according to the tested environment.

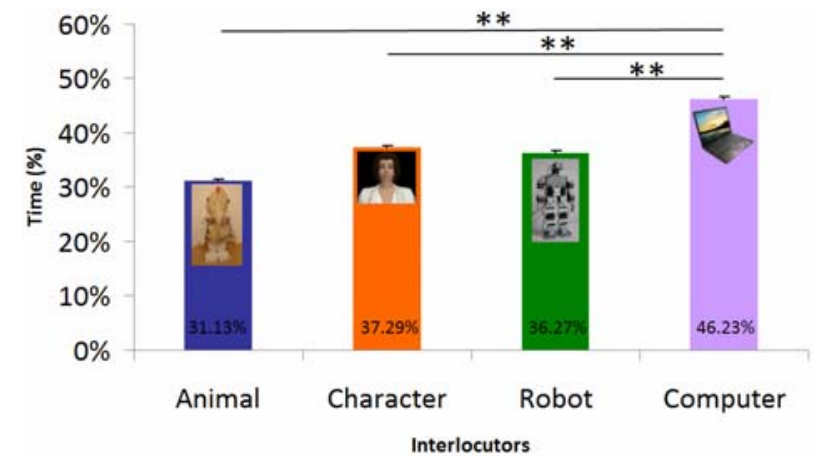

Fig. 7. Time watching the computer

Wilcoxon's test $(*: \mathrm{P}<0.012$; ** : $\mathrm{P}<0.0025 ; * * *$ : $\mathrm{P}<0.00025$ with Bonferroni's corrections). $\mathrm{N}=51$

\section{Observation analysis: smiles to interlocutors}

The second part of this study consisted to analyze children's smiles. The objective was to determine whether the children smiled more or less frequently in the presence of the character, the animal or the robot in comparison of smiles in the presence of the computer. Results revealed that children smiled less frequently in the presence of the computer (Wilcozon's test, robot: $\mathrm{Z}=3.78, \mathrm{P}<0.001$, animal: $\mathrm{Z}=4.3, \mathrm{P}<0.0001$; character: $\mathrm{Z}=2,351, \mathrm{P}=0.019$, Fig. 8 ). The maximum number of smiles appeared in the presence of the character. Fig. 8 shows the average numbers of smiles per minute.

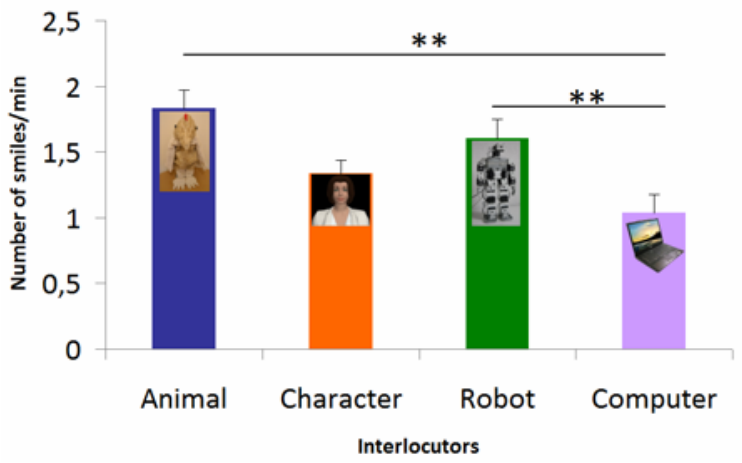

Fig. 8. Number of smiles

Wilcoxon's test $(*: \mathrm{P}<0.012 ; * *: \mathrm{P}<0.0025$; *** : $\mathrm{P}<0.00025$ with Bonferroni's corrections). $\mathrm{N}=51$
We can notice that children showed more interest (looks) and more satisfaction (smiles) with robots and avatar than with computer.

\section{Performance analysis: time and mistakes}

The last analysis consisted to examine children's performances in terms of response time and numbers of mistakes during mental arithmetic exercises.

Comparing the computer to other environments, results indicated that there was no response time difference (Wilcoxon's tests, level 1: $\mathrm{Z}=0.825, \mathrm{P}=0.409$; level 2: $\mathrm{Z}=0.112, \mathrm{P}=1.903$, level 3: $\mathrm{Z}=0.057 ; \mathrm{P}=0.910$; level 4: $\mathrm{Z}=0$,862, $\mathrm{P}=0.388$; level 5: $\mathrm{Z}=0.526, \mathrm{P}=0.599$ ). Moreover, there was no difference about the number of mistakes (Chisquare test, $\mathrm{ddl}=1, \mathrm{P}>0.05$ ).

Comparing the character to both robots, response times were longer when the children was in interaction with robots than with character, in levels 1 and 2 (Wilcoxon's tests, level 1: $\mathrm{Z}=2.419, \mathrm{P}=0.016$ and level 2 : $\mathrm{Z}=2.418, \mathrm{P}=0.007$ ). There were no significant difference in levels 3,4 and 5 (Wilcoxon's tests, level 3: $\mathrm{Z}=0.719, \mathrm{P}=0.472$; level 4: $\mathrm{Z}=0.028, \mathrm{P}=0.978$ and level $5: \mathrm{Z}=1.627, \mathrm{P}=0.104$ ).

Comparing the character to the animal, response times were the longest when the children was in interaction with the animal in level 1 and 2 (Wilcoxon'tests, level 1: $\mathrm{Z}=$ 3.099, $\mathrm{P}=0.002$ and level 2: $\mathrm{Z}=3.089, \mathrm{P}=0.002$ ). Fig. 9 shows the average response times per level according to the tested environment.

Concerning the number of mistakes, there were significantly no difference between the both robots and the character (Chi-square, $\mathrm{ddl}=1, \mathrm{P}<0.05$ ).

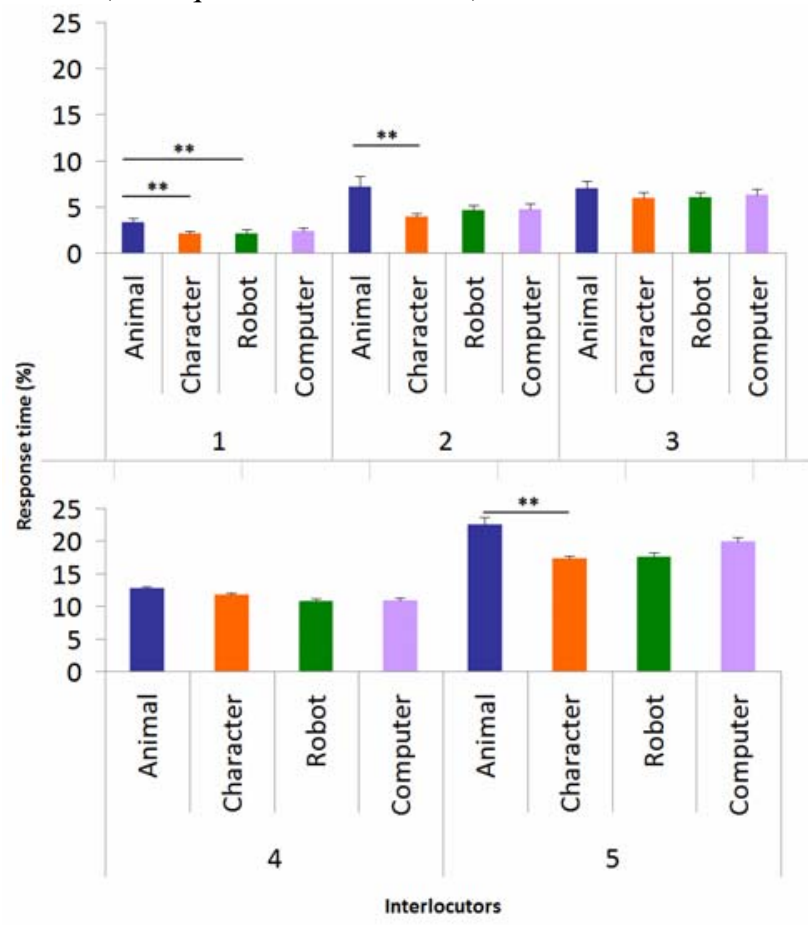

Fig. 9. Response times per level

Wilcoxon's test $(*: \mathrm{P}<0.012 ; * *: \mathrm{P}<0.0025 ; * * *$ : $\mathrm{P}<0.00025$ with Bonferroni's corrections). $\mathrm{N}=51$ 
Concerning mental arithmetic, the longest response times occurred when children were in interaction with the animal. According to Michael [15], animals do not judge. That is the reason why they are often used in therapy as mediators between doctors and patients. In this case, patients stress and anxiety can decrease (Martin \& Farnum [16], Bass et al [17]). It seems that children are more stressed when they are with the robot or the character (which both have a human appearance) than with the animal. The human appearance might increase concentration and/or motivation.

\section{CONCLUSION AND PERSPECTIVES}

New kinds of companions are growing: robots, virtual characters, learning software... It is essential to evaluate their humans' acceptability and to develop techniques which improve the interaction. Our experimentation studied the influence of three animated objects whereas most of the others focused on one object (Nabe et al [18], Svenstrup et al [19], Weiss et al [20] and Beran et al [21]).

This study came from a coupling of two disciplines (computing science and ethology) and compiled three approaches: questionnaire, observation and performance. It gave three main results:

- Children preferred the humanoid metallic robot first. The plush robot came in second place. The third favorite companion was the virtual character. And the last one was the computer.

- Children showed more interest and more satisfaction in the presence of animated objects.

- Children seemed to obtain better performances with anthropomorphic animated objects. But, even if others animated objects did not increase performances, they appeared to be beneficial for children in terms of interests and satisfaction.

Analysis is currently being realized in order to study more precisely children's behavioral reactions. Two perspectives seem interesting:

- Studying specific periods of the interaction like uncertainty or doubts. It can reveal relevant attitudes.

- Studying more precisely children's reactions face to the different animated objects.

Our study showed that robots were the favorite interlocutor in the context of cognitive exercises. It revealed that robots appearance was not a determining acceptability factor. Each companion had the same speech with the same voice and had a poor non verbal behavior. The next experimentation will compare two similar robots having two different behaviors in order to study attachment levels. The objective will be to determine whether a robot should have a specific personality to be better accepted.

\section{REFERENCES}

[1] M. Chetouani, Y. H. Wu, C. Jost, B. Le Pevedic, C. Fassert, V. Cristancho-Lacroix, S. Lassiaille, C. Granata, A. Tapus, D. Duhaut, and others, "Cognitive Services for Elderly People: The ROBADOM project,” 2010.

[2] Y.-H. Wu, C. Fassert, and A.-S. Rigaud, "Designing robots for the elderly: Appearance issue and beyond," Archives of Gerontology and Geriatrics, vol. 54, no. 1, pp. 121-126, Jan. 2012.

[3] C. Jost, B. Le Pevedic, and D. Duhaut, "Robot is best to play with human!,” presented at the 21st IEEE International Symposium on Robot and Human Interactive Communication, Paris, 2012.

[4] E. Hudlicka, S. Payr, R. Ventura, C. Becker-Asano, K. Fischer, I. Leite, and C. Von, "Social interaction with robots and agents: Where do we stand, where do we go?,” 2009, pp. 1-6.

[5] M. Dragone, B. R. Duffy, and G. M. P. O’Hare, "Social interaction between robots, avatars \& amp; humans,” pp. 24-29.

[6] C. D. Kidd, "Sociable robots: The role of presence and task in human-robot interaction," Massachusetts Institute of Technology, 2003.

[7] K. Shinozawa, F. Naya, J. Yamato, and K. Kogure, "Differences in effect of robot and screen agent recommendations on human decision-making," International Journal of Human-Computer Studies, vol. 62, no. 2, pp. 267-279, Feb. 2005.

[8] J. Yamato, K. Shinozawa, F. Naya, and K. Kogure, "Evaluation of Communication with Robot and Agent: Are robots better social actors than agents," in Proc. of the 8th IFIP TC. 13 Int. Conf. on Human-Computer Interaction (INTERACT'01), 2001, pp. 9-13.

[9] K. M. Lee, Y. Jung, J. Kim, and S. R. Kim, "Are physically embodied social agents better than disembodied social agents?: The effects of physical embodiment, tactile interaction, and people's loneliness in human-robot interaction," International Journal of Human-Computer Studies, vol. 64, no. 10, pp. 962-973, Oct. 2006.

[10] K. Ohara, S. Negi, T. Takubo, Y. Mae, and T. Arai, "Evaluation of virtual and real robot based on human impression,” 2009, pp. 873878.

[11] S.-H. Hsu, C.-Y. Chou, F.-C. Chen, Yuan-Kai, and T.-W. Chan, "An investigation of the differences between robot and virtual learning companions' influences on students' engagement,” 2007, pp. 41-48.

[12] T. Nomura and M. Sasa, "Investigation of differences on impressions of and behaviors toward real and virtual robots between elder people and university students,” 2009, pp. 934-939.

[13] A. Tapus, C. Tapus, and M. Mataric, "The role of physical embodiment of a therapist robot for individuals with cognitive impairments," 2009, pp. 103-107.

[14] E. de Sevin, R. Niewiadomski, E. Bevacqua, A. M. Pez, M. Mancini, and C. Pelachaud, "Greta, une plateforme d'agent conversationnel expressif et interactif," Technique et Science Informatiques, vol. 29, no. 7, p. 751, 2010.

[15] E. Michaels, "Pets and the elderly: a therapeutic friendship.," Canadian Medical Association Journal, vol. 127, no. 1, p. 70, 1982.

[16] F. Martin and J. Farnum, "Animal-Assisted Therapy for Children with Pervasive Developmental Disorders," Western Journal of Nursing Research, vol. 24, no. 6, pp. 657-670, Oct. 2002.

[17] M. M. Bass, C. A. Duchowny, and M. M. Llabre, "The Effect of Therapeutic Horseback Riding on Social Functioning in Children with Autism," Journal of Autism and Developmental Disorders, vol. 39, no. 9, pp. 1261-1267, Apr. 2009.

[18] S. Nabe, T. Kanda, K. Hiraki, H. Ishiguro, K. Kogure, and N. Hagita, "Analysis of human behavior to a communication robot in an open field," 2006, p. 234.

[19] M. Svenstrup, T. Bak, O. Maler, H. J. Andersen, and O. B. Jensen, "Pilot Study of Person Robot Interaction in a Public Transit Space," in Research and Education in Robotics - EUROBOT 2008, vol. 33, A. Gottscheber, S. Enderle, and D. Obdrzalek, Eds. Berlin, Heidelberg: Springer Berlin Heidelberg, 2009, pp. 96-106.

[20] A. Weiss, D. Wurhofer, and M. Tscheligi, “I Love This Dog'Children's Emotional Attachment to the Robotic Dog AIBO," International Journal of Social Robotics, vol. 1, pp. 243-248, Jun. 2009.

[21] T. N. Beran, A. Ramirez-Serrano, R. Kuzyk, S. Nugent, and M. Fior, "Would Children Help a Robot in Need?," International Journal of Social Robotics, vol. 3, pp. 83-93, Sep. 2010. 